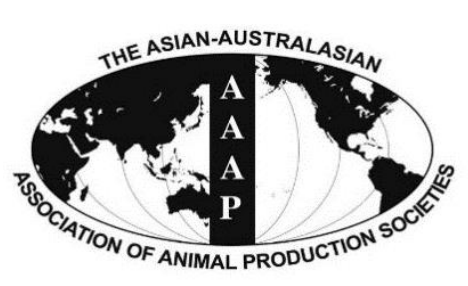

Open Access

Asian Australas. J. Anim. Sci.

Vol. 29, No. 9 : 1215-1221 September 2016

http://dx.doi.org/10.5713/ajas.15.0754

www.ajas.info

pISSN 1011-2367 elSSN 1976-5517

\title{
Prediction of Carcass Composition Using Carcass Grading Traits in Hanwoo Steers
}

\author{
Jooyoung Lee, Seunggun Won, Jeongkoo Lee, and Jongbok Kim* \\ College of Animal Life Science, Kangwon National University, Chuncheon 24341, Korea
}

\begin{abstract}
The prediction of carcass composition in Hanwoo steers is very important for value-based marketing, and the improvement of prediction accuracy and precision can be achieved through the analyses of independent variables using a prediction equation with a sufficient dataset. The present study was conducted to develop a prediction equation for Hanwoo carcass composition for which data was collected from 7,907 Hanwoo steers raised at a private farm in Gangwon Province, South Korea, and slaughtered in the period between January 2009 and September 2014. Carcass traits such as carcass weight (CWT), back fat thickness (BFT), eye-muscle area (EMA), and marbling score (MAR) were used as independent variables for the development of a prediction equation for carcass composition, such as retail cut weight and percentage (RC, and \% RC, respectively), trimmed fat weight and percentage (FAT, and \%FAT, respectively), and separated bone weight and percentage (BONE, and \%BONE), and its feasibility for practical use was evaluated using the estimated retail yield percentage (ELP) currently used in Korea. The equations were functions of all the variables, and the significance was estimated via stepwise regression analyses. Further, the model equations were verified by means of the residual standard deviation and the coefficient of determination $\left(\mathrm{R}^{2}\right)$ between the predicted and observed values. As the results of stepwise analyses, CWT was the most important single variable in the equation for RC and FAT, and BFT was the most important variable for the equation of $\%$ RC and \%FAT. The precision and accuracy of three variable equation consisting CWT, BFT, and EMA were very similar to those of four variable equation that included all for independent variables (CWT, BFT, EMA, and MAR) in RC and FAT, while the three variable equations provided a more accurate prediction for $\%$ RC. Consequently, the three-variable equation might be more appropriate for practical use than the four-variable equation based on its easy and cost-effective measurement. However, a relatively high average difference for the ELP in absolute value implies a revision of the official equation may be required, although the current official equation for predicting RC with three variables is still valid. (Key Words: Carcass Composition, Carcass Grading Traits, Coefficient of Determination, Hanwoo Steer, Prediction Equation, Residual Standard Deviation)
\end{abstract}

\section{INTRODUCTION}

Carcass composition is important for value-based marketing of a carcass and for the establishment of an optimal feeding scheme (Drennan et al., 2008; Minchin, et al., 2009). However, the actual values of composition obtained from carcass dissection may not facilitate the determination of carcass pricing because the pricing of carcasses is typically completed prior to the carcass dissection. Thus, many studies have focused on the development of equations that predict carcass composition

\footnotetext{
* Corresponding Author: Jongbok Kim. Tel: +82-33-250-8624, Fax: +82-33-244-2532, E-mail: jbkim@kangwon.ac.kr Submitted Sept. 9, 2015; Revised Oct. 29, 2015; Accepted Nov. 26, 2015
}

based on carcass traits, such as carcass weight (CWT), backfat thickness (BFT), eye-muscle area (EMA), marbling score (MAR), and the percentage of kidney, pelvic and heart fat (\% KPH) (Greiner et al., 2003b). Various efforts have been made to improve the prediction equation using a large dataset and focusing on the reduction of differences between the predicted and observed values with a low standard error for the estimate (Kauffman et al., 1975) and further ultrasonic measurement of fat has been widely used for the development of a prediction equation (Anderson et al., 1983; Herring et al., 1994). However, ultrasound technology may not be available at the farm level and the official equation includes three independent carcass variables (CWT, BFT, and EMA) and is widely used to estimate the percentage of retail cut for the Hanwoo carcasses (MAFRA, 2009a); 
several studies have been conducted to develop an equation with improved predictive ability for Hanwoo carcasses (Lee et al., 2005; 2008; Choy et al., 2010). However, the development and proof of prediction equations must be continuously reconfirmed due to the environmental changes in the beef production system and the endless efforts to genetically improve the cattle to ensure high productivity, which could lead to biological changes in Hanwoo cattle that could affect feed efficiency, growth performance, and body composition (Kim and Lee, 2000).

Thus, this study aimed to develop equations to predict carcass composition, such as retail cut, trimmed fat and separable bone weights and percentages, of Hanwoo steer using carcass traits (CWT, BFT, EMA, and MAR) on the steer field data collected from the private farm of Korea and to verify the predictive ability of the model equation developed.

\section{MATERIALS AND METHODS}

\section{Animals and traits}

Data were obtained from 7,907 Hanwoo steers raised at a private farm in Gangwon Province, South Korea, and slaughtered in the period between January 2009 and September 2014. The number of animals per slaughter year were $1,162,1,227,1,857,1,450,1,168$, and 1,043 for year 2009, 2010, 2011, 2012, 2013, and 2014, respectively, and mean age in month was $31.97 \pm 3.22$. The feeding and management of the steers has been explained by Koh et al. (2014).

Following the standard normal industrial procedures recommended by the Korean government (MAFRA, 2009a), the slaughtering of the steers was conducted at an abattoir that was located at a transport distance less than an hour from the steer farm by truck. After slaughtering, each carcass was immediately halved and held in a chilling room at $4{ }^{\circ} \mathrm{C}$ for one night, and then both sides of the carcasses were taken from the chilling room and transferred to the evaluation venue for the weight measurement. The left sides were dissected at the position between the last rib and the first lumbar vertebra, and these were used for the measurements of BFT, EMA, and MAR. The BFT was measured at the three-fourths position of the longissimus muscle from the spinal column. The EMA was measured using a transparent grid. The MAR was evaluated from 1 (poor) to 9 (best) according to the Korea Beef Marbling Standard, and the estimated retail yield percentage (ELP) was calculated according to the Korea Beef Grading Standards as follows.

$$
\begin{aligned}
\operatorname{ELP}(\%) & =71.414-(0.625 \times B F T) \\
& +(0.130 \times E M A)-(0.024 \times C W T)
\end{aligned}
$$

Carcass fabrication procedures were performed at the adjacent commercial packing plant based on the standards recommended by the Korean government (MAFRA, 2009b). The entire carcass was dissected into several sub-primal cuts, and all bones were removed with the exception of the ribs. Rib bones were left in the rib. After the de-boning, the excessive fat and intermuscular fat were closely trimmed.

All sub-primal cuts were summed as retail cut weight (RC), while the bones removed from the sub-primal cuts and tail were summed as bone weight (BONE). The trimmed fat weight (FAT) was calculated by subtracting the RC and BONE from the CWT, since the measurement of FAT was not possible due to the conditions of the packing plant. The percentages for the retail cuts (\%RC), separated bones (\%BONE), and trimmed fats (\%FAT) were obtained based on the cold CWT.

After data collection, the unrealistic values that were regarded as recording errors were deleted, and the furthest values from the normal, as determined by 3 standard deviations from the mean values in the ratios of RC to FAT, $\mathrm{RC}$ to BONE, and FAT to BONE, were excluded (Hickey et al., 2007; McPhee et al., 2008). A total of 7,152 carcass records were used in the subsequent statistical analyses.

\section{Statistical analyses}

A randomly determined half of the 7,152 records $(n=$ $3,576)$ was assigned to the development of prediction equations, while the other half of the dataset $(n=3,576)$ was assigned to verifying the equations developed. The simple statistics for the development and test datasets are presented in Table 1.

The prediction equations for the six carcass compositional traits-RC, \%RC, FAT, \%FAT, BONE, and \%BONE-were developed using a stepwise regression procedure, using CWT, BFT, EMA, and MAR as independent variables that had to retain statistical significance $(p<0.05)$ within the model equation. The predictive ability of the equations developed was determined by the coefficient of determination $\left(\mathrm{R}^{2}\right)$ and the residual standard deviation (RSD), and the equations with the highest $\mathrm{R}^{2}$ and the lowest RSD values were considered to have the best predictive ability.

The difference and correlation coefficients between the predicted and observed values were calculated using the dataset and the equations developed in this study and compared to the predictive ability of the equations. In addition, since ELP represents the predicted percentage of retail yield calculated by the current official equation for Hanwoo carcasses, the difference and correlation coefficients between the ELP and \% RC observed were compared to those values calculated from the $\% \mathrm{RC}$ equations developed in this study, whereby the feasibility of the \% RC equations were evaluated for practical use.

All the statistical analyses, including the elementary statistics, correlation coefficients, and stepwise regressions, 
Table 1. Simple statistics for the independent and dependent variables in the development dataset $(n=3,576)$ and the test dataset $(\mathrm{n}=3,576)$

\begin{tabular}{|c|c|c|c|c|c|c|}
\hline \multirow[t]{2}{*}{ Traits } & \multicolumn{3}{|c|}{$\begin{array}{l}\text { For equation } \\
\text { development }\end{array}$} & \multicolumn{3}{|c|}{$\begin{array}{c}\text { For test of equation } \\
\text { developed }\end{array}$} \\
\hline & Mean & SD & $\mathrm{CV}$ & Mean & SD & $\mathrm{CV}$ \\
\hline$\overline{\mathrm{CWT}(\mathrm{kg})}$ & 454.0 & 45.5 & 10.03 & 453.3 & 44.9 & 9.9 \\
\hline $\operatorname{BFT}(\mathrm{mm})^{1}$ & 14.8 & 5.0 & 34.0 & 14.8 & 4.9 & 33.1 \\
\hline $\operatorname{EMA}\left(\mathrm{cm}^{2}\right)^{1}$ & 96.2 & 10.6 & 11.0 & 95.8 & 10.6 & 11.1 \\
\hline MAR $^{1,2}$ & 6.3 & 1.7 & 27.4 & 6.3 & 1.7 & 27.2 \\
\hline $\operatorname{ELP}(\%)^{3}$ & 60.6 & 3.7 & 6.0 & 60.5 & 3.6 & 5.9 \\
\hline $\mathrm{RC}(\mathrm{kg})$ & 279.2 & 28.8 & 10.3 & 278.8 & 28.2 & 10.1 \\
\hline$\% \mathrm{RC}(\%)^{4}$ & 61.5 & 2.6 & 4.2 & 61.6 & 2.5 & 4.1 \\
\hline FAT (kg) & 121.1 & 20.3 & 16.7 & 120.7 & 20.1 & 16.7 \\
\hline$\%$ FAT $(\%)^{4}$ & 26.6 & 2.9 & 10.9 & 26.6 & 2.9 & 10.9 \\
\hline BONE $(\mathrm{kg})$ & 53.7 & 5.3 & 9.8 & 53.7 & 5.2 & 9.7 \\
\hline$\%$ BONE $(\%)^{4}$ & 11.9 & 1.0 & 7.9 & 11.9 & 0.9 & 7.9 \\
\hline
\end{tabular}

SD, standard deviation; CV, coefficient of variation; CWT, cold carcas weight; BFT, back fat thickness; EMA, eye-muscle area $\left(\mathrm{cm}^{2}\right)$; MAR, marbling score; ELP, estimated lean yield percentage; RC, retail cut weight; \%RC, retail cut percentage; FAT, trimmed fat weight; \%FAT, trimmed fat percentage; BONE, trimmed bone weight; \%BONE, trimmed bone percentage.

${ }^{1}$ Measured from the last rib to the first lumbar vertebra cross-sectioned.

${ }^{2}$ Evaluated based on the Korean Beef Marbling Standard with scores from 1 (poor) to 9 (best)

${ }^{3}$ Estimated retail cut percentage using the current official equation for Hanwoo carcasses (ELP $=71.414-0.024$ CWT-0.625 BFT+0.130 EMA)

${ }^{4}$ Percentages for cold carcass weight.

were performed using SAS software (Version 9.2, SAS Inst., Inc., Cary, NC, USA)

\section{RESULTS}

\section{Stepwise regressions for $\mathrm{RC}$ and \% RC}

Stepwise regression equations for predicting $\mathrm{RC}$ and \% RC from the four carcass grading traits of CWT, BFT, EMA, and MAR are shown in Table 2. For presentation purposes, the equations for each step of the regression analyses were labeled as Eq. 1, Eq. 2, Eq. 3, and Eq. 4, respectively.

The CWT was the most important for the prediction of $\mathrm{RC}$, since $\mathrm{CWT}$ alone governed $\mathrm{RC}$ values with a variation of $83.4 \%$. For \%RC, the BFT covered $10.7 \%$ of the variation of \% RC (Eq. 1). The EMA was the second most influential variable on both $\mathrm{RC}$ and \% RC, and it increased the power of predictability an additional $2.5 \%$ and $9.2 \%$ of variations in $\mathrm{RC}$ and \% RC, respectively (Eq. 2). The MAR was the last variable in the equation for $\mathrm{RC}$ and $\% \mathrm{RC}$ in the stepwise process, but its influence on the increase in the $\mathrm{R}^{2}$ value was not significant.

The RSD and $\mathrm{R}^{2}$ of Eq. 3 with three independent variables were estimated as $10.350 \mathrm{~kg}$ and $87.1 \%$, respectively, and the values for Eq. 4 in which MAR was added were $10.342 \mathrm{~kg}$ and $87.1 \%$, respectively. The RSD and $\mathrm{R}^{2}$ between Eq. 3 and Eq. 4 showed little difference for the dependent variables of RC and \% RC.

\section{Stepwise regressions for FAT and \%FAT}

The results of the stepwise regression analyses for predicting FAT and \%FAT are presented in Table 3. The CWT again governed the equation, accounting for $59.7 \%$ of the variations for FAT. The second variable, BFT, was added to the equation for FAT, which resulted in an increase of the $\mathrm{R}^{2}$ value by $5.3 \%$, while the further addition of EMA increased the $\mathrm{R}^{2}$ value to $68.8 \%$. The MAR was the last variable in the equation, but its contribution to the variation in FAT was insignificant and induced an increase of only $0.2 \%$ in the equation evaluation with three variables (Eq. 3).

In the stepwise analyses for \%FAT, the most influential

Table 2. Regression equations for predicting weight in kilograms (RC) and percentage of retail cut (\% RC) using carcass traits

\begin{tabular}{|c|c|c|c|c|c|c|c|}
\hline \multirow{2}{*}{$\begin{array}{l}\text { Dependent variable } \\
\text { and equation no. }\end{array}$} & \multirow{2}{*}{ RSD } & \multirow{2}{*}{$\mathrm{R}^{2}(\%)$} & \multirow{2}{*}{ Intercept } & \multicolumn{4}{|c|}{ Partial regression coefficients* } \\
\hline & & & & CWT & $\mathrm{BFT}^{1}$ & EMA $^{1}$ & MAR $^{1,2}$ \\
\hline \multicolumn{8}{|l|}{$\overline{\mathrm{RC}}$} \\
\hline Eq. 1 & 11.714 & 83.4 & 17.351 & 0.576 & - & - & - \\
\hline Eq. 2 & 10.796 & 85.9 & -6.043 & 0.527 & - & 0.479 & - \\
\hline Eq. 3 & 10.350 & 87.1 & -6.529 & 0.556 & -0.658 & 0.446 & - \\
\hline Eq. 4 & 10.342 & 87.1 & -5.926 & 0.556 & -0.659 & 0.459 & -0.268 \\
\hline \multicolumn{8}{|l|}{$\% \mathrm{RC}^{3}$} \\
\hline Eq. 1 & 2.425 & 10.7 & 63.997 & - & -0.167 & - & - \\
\hline Eq. 2 & 2.297 & 19.9 & 57.094 & - & -0.179 & 0.074 & - \\
\hline Eq. 3 & 2.248 & 23.3 & 60.041 & -0.012 & -0.142 & 0.096 & - \\
\hline Eq. 4 & 2.246 & 23.5 & 60.178 & -0.013 & -0.143 & 0.099 & -0.061 \\
\hline
\end{tabular}

RSD, residual standard deviations for the model; CWT, cold carcass weight (kg); BFT, back fat thickness (mm); EMA, eye-muscle area (cm²); MAR, marbling score.

${ }^{1}$ Measured from the last rib to the first lumbar vertebra cross-sectioned.

${ }^{2}$ Evaluated based on the Korean Beef Marbling Standard with scores of 1 (poor) to 9 (best).

${ }^{3}$ Percentages for cold carcass weight.

* Variables in the models included only those that were significant at $\mathrm{p}<0.05$ 
Table 3. Regression equations for predicting weight in kilograms (FAT) and percentage of trimmed fat (\%FAT) using carcass traits

\begin{tabular}{|c|c|c|c|c|c|c|c|}
\hline \multirow{2}{*}{$\begin{array}{l}\text { Dependent variable } \\
\text { and equation no. }\end{array}$} & \multirow{2}{*}{ RSD } & \multirow{2}{*}{$\mathrm{R}^{2}(\%)$} & \multirow{2}{*}{ Intercept } & \multicolumn{4}{|c|}{ Partial regression coefficients* } \\
\hline & & & & CWT & $\mathrm{BFT}^{1}$ & $\mathrm{EMA}^{1}$ & MAR $^{1,2}$ \\
\hline \multicolumn{8}{|l|}{ FAT } \\
\hline Eq. 1 & 12.889 & 59.7 & -35.069 & 0.344 & - & - & - \\
\hline Eq. 2 & 12.004 & 65.0 & -31.936 & 0.305 & 1.000 & - & - \\
\hline Eq. 3 & 11.340 & 68.8 & -11.826 & 0.351 & 0.917 & -0.417 & - \\
\hline Eq. 4 & 11.298 & 69.0 & -13.173 & 0.352 & 0.918 & -0.446 & 0.600 \\
\hline \multicolumn{8}{|l|}{$\% \mathrm{FAT}^{3}$} \\
\hline Eq. 1 & 2.633 & 17.7 & 23.017 & - & 0.243 & - & - \\
\hline Eq. 2 & 2.566 & 21.9 & 28.261 & - & 0.252 & -0.056 & - \\
\hline Eq. 3 & 2.471 & 27.6 & 23.946 & 0.018 & 0.198 & -0.089 & - \\
\hline Eq. 4 & 2.462 & 28.2 & 23.644 & 0.018 & 0.199 & -0.095 & 0.134 \\
\hline
\end{tabular}

RSD, residual standard deviations for the model; CWT, cold carcass weight (kg); BFT, back fat thickness (mm); EMA, eye-muscle area (cm²); MAR, marbling score.

${ }^{1}$ Measured from the last rib to the first lumbar vertebra cross-sectioned.

${ }^{2}$ Evaluated based on the Korean Beef Marbling Standard with scores of 1 (poor) to 9 (best)

${ }^{3}$ Percentages for cold carcass weight.

* Variables in the models included only those that were significant at $\mathrm{p}<0.05$.

factors in the equation were BFT, EMA, CWT, and MAR, in this order, and the addition of EMA and CWT in the equation with BFT resulted in an increase of the $\mathrm{R}^{2}$ by $9.9 \%$ in the equation (from $17.7 \%$ in Eq. 1 to $27.6 \%$ in Eq. 3). However, the addition of MAR showed an increase in the $\mathrm{R}^{2}$ of only $0.6 \%$ for the equation fit (from $27.6 \%$ in Eq. 3 to $28.2 \%$ in Eq. 4).

\section{Stepwise regressions for $\mathrm{BONE}$ and \% $\mathrm{BONE}$}

The results of the stepwise analyses for predicting BONE and \%BONE are delineated in Table 4. The CWT and EMA were the first and last variables, respectively, entered into the equation for predicting BONE and \%BONE. As the third variable, MAR with $\mathrm{CWT}$ and BFT improved BONE and $\%$ BONE by $1.3 \%$ and $2.0 \%$, respectively.
The $\mathrm{R}^{2}$ values in Eq. 3 and Eq. 4 for BONE were $53.3 \%$ and $53.4 \%$, respectively, which corresponded with $27.5 \%$ and $27.6 \%$ for $\% \mathrm{BONE}$, respectively. The differences in $\mathrm{R}^{2}$ and RSD between the final four-variable equation (Eq. 4) and the three-variable equation in the third step (Eq. 3) were not very significant in BONE and \%BONE.

\section{Evaluation of the equation}

The three- and four-variable equations (Eq. 3 and 4, respectively) were selected as the best probable equations because of their high $\mathrm{R}^{2}$ and small RSD, and they were applied to the test dataset for the evaluation of the equations. Each dependent variable predicted from Eq. 3 and Eq. 4 were compared with an extra retail cut percentage from the official equation (ELP).

Table 4. Regression equations for predicting weight in kilograms (BONE) and percentage of trimmed bone (\%BONE) using carcass traits

\begin{tabular}{|c|c|c|c|c|c|c|c|}
\hline \multirow{2}{*}{$\begin{array}{l}\text { Dependent variable } \\
\text { and equation no. }\end{array}$} & \multirow{2}{*}{ RSD } & \multirow{2}{*}{$\mathrm{R}^{2}(\%)$} & \multirow{2}{*}{ Intercept } & \multicolumn{4}{|c|}{ Partial regression coefficients* } \\
\hline & & & & CWT & $\mathrm{BFT}^{1}$ & EMA $^{1}$ & MAR $^{1,2}$ \\
\hline \multicolumn{8}{|l|}{$\overline{\mathrm{BONE}}$} \\
\hline Eq. 1 & 3.834 & 47.0 & 17.717 & 0.079 & - & - & - \\
\hline Eq. 2 & 3.647 & 52.0 & 16.927 & 0.089 & -0.252 & - & - \\
\hline Eq. 3 & 3.597 & 53.3 & 18.530 & 0.091 & -0.257 & - & -0.351 \\
\hline Eq. 4 & 3.596 & 53.4 & 19.099 & 0.092 & -0.259 & -0.014 & -0.331 \\
\hline \multicolumn{8}{|l|}{$\% \mathrm{BONE}^{3}$} \\
\hline Eq. 1 & 0.851 & 18.0 & 15.836 & -0.009 & - & - & - \\
\hline Eq. 2 & 0.811 & 25.5 & 15.665 & -0.007 & -0.055 & - & - \\
\hline Eq. 3 & 0.800 & 27.5 & 16.023 & -0.006 & -0.056 & - & -0.078 \\
\hline Eq. 4 & 0.799 & 27.6 & 16.178 & -0.006 & -0.056 & -0.004 & -0.073 \\
\hline
\end{tabular}

RSD, residual standard deviations for the model; CWT, cold carcass weight (kg); BFT, back fat thickness (mm); EMA, eye-muscle area (cm²); MAR, marbling score.

${ }^{1}$ Measured from the last rib to the first lumbar vertebra cross-sectioned.

${ }^{2}$ Evaluated based on the Korean Beef Marbling Standard with scores of 1 (poor) to 9 (best).

${ }^{3}$ Percentages for cold carcass weight.

* Variables in the models included only those that were significant at $\mathrm{p}<0.05$ 
Table 5 indicated the means predicted from Eq. 3 and Eq. 4 and observed from the test dataset. Eq. 3 and Eq. 4 were evaluated using the average differences and the correlation coefficients. The differences between the predicted and observed values were calculated by subtracting the observed value from the predicted value.

The correlation coefficients between the predicted and observed values in Eq. 3 were almost the same as those in Eq. 4 for every dependent variable, and the correlation coefficients of RC, FAT, and BONE were higher than those of \% RC, \% FAT, and \%BONE in both Eq. 3 and Eq. 4.

The differences between the predicted and observed values for $\% \mathrm{RC}$ and \%BONE were statistically determined using a T-test in Eq. 3 and for \% RC, \%FAT, and \%BONE in Eq. 4. Eq. 3, with three variables, overestimated \%RC and \%BONE, while Eq. 4 underestimated \% RC, BONE, and \%BONE. Using the ELP (official equation) for prediction, the average differences of $\% \mathrm{RC}$, with an absolute value of 1.01 , were higher than the differences of 0.15 and 0.28 from Eq. 3 and Eq. 4, respectively, and the average differences from Eq. 3 tended to be smaller than those from Eq. 4 for all dependent variables, except RC, for which the average difference in Eq. 3 was slightly higher.

\section{DISCUSSION}

The model equation in the final step was functions of all four carcass-grading traits (CWT, BFT, EMA, and MAR) in order to obtain each dependent variables. The MAR was the last variable in the equation for RC, \% RC, FAT, and \% FAT, while the EMA was the last for BONE and \%BONE. However, compared to the RSD and $\mathrm{R}^{2}$ values, there were no practical differences between Eq. 3 and Eq. 4, which indicates that the last variables in the equation rarely contributed to the predictive ability of the equation. The inclusion of MAR, as the last variable in Eq. 3, with CWT, BFT, and EMA, increased the $\mathrm{R}^{2}$ value of the equation for $\%$ RC and \%FAT by only $0.02 \%$ and $0.06 \%$, respectively (Tables 2 and 3). The inclusion of EMA, as the last variable in the Eq. 3, with CWT, BFT, and MAR increased the $\mathrm{R}^{2}$ value of the equation for both BONE and \%BONE by only $0.01 \%$ (Table 4 ).

The low contribution of MAR to the predictive ability of the equation for \% RC and \%FAT differs from the results of Griffin et al. (1999) and Greiner et al. (2003a), where the addition of MAR to the equation for $\% \mathrm{RC}$, which consisted of four independent variables (CWT, BFT, the percentage of kidney, pelvic and heart fat [\% $\mathrm{KPH}]$, and EMA), increased the model $\mathrm{R}^{2}$ values by sizable amounts ( $2 \%$ to $4 \%$ ). The low contribution of MAR in predicting $\% \mathrm{RC}$ and $\% \mathrm{FAT}$ in this study could be due to a low correlation between MAR and \% RC and \%FAT in Hanwoo steer carcasses. Koh et al. (2014) reported a small and positive phenotypic correlation between MAR and \% RC and \%FAT in Hanwoo steer data (r $=+0.04$ and +0.07 , respectively), of which similar and positive correlation coefficients of +0.02 and +0.03 were estimated in the preliminary analyses of this study (data not shown).

On the contrary, many previous studies in the US have shown a negative and moderate correlation between MAR

Table 5. Predicted and observed mean and average difference and correlation coefficients between the predicted and observed values for the dependent variables using the prediction equation with the test dataset $(n=3,576)$

\begin{tabular}{|c|c|c|c|c|c|}
\hline Dependent & Equations $^{1}$ & Predicted mean & Observed mean & Average difference ${ }^{2}$ & $\begin{array}{l}\text { Correlation } \\
\text { coefficients }^{3}\end{array}$ \\
\hline \multirow[t]{2}{*}{$\overline{\mathrm{RC}}$} & Eq. 3 & 278.52 & & -0.31 & 0.93 \\
\hline & Eq. 4 & 278.67 & 278.83 & -0.16 & 0.93 \\
\hline \multirow[t]{3}{*}{$\% \mathrm{RC}$} & Eq. 3 & 61.70 & & $0.15^{* * *}$ & 0.49 \\
\hline & Eq. 4 & 61.28 & & $-0.28 * * *$ & 0.50 \\
\hline & ELP $^{4}$ & 60.54 & 61.55 & $-1.01 * * *$ & 0.49 \\
\hline \multirow[t]{2}{*}{ FAT } & Eq. 3 & 120.86 & & 0.13 & 0.84 \\
\hline & Eq. 4 & 120.97 & 120.73 & 0.24 & 0.84 \\
\hline \multirow[t]{2}{*}{$\%$ FAT } & Eq. 3 & 26.50 & & -0.05 & 0.54 \\
\hline & Eq. 4 & 26.48 & 26.55 & -0.07 & 0.55 \\
\hline \multirow[t]{2}{*}{ BONE } & Eq. 3 & 53.78 & & 0.04 & 0.72 \\
\hline & Eq. 4 & 53.56 & 53.74 & $-0.18 * *$ & 0.72 \\
\hline \multirow[t]{2}{*}{$\%$ BONE } & Eq. 3 & 11.99 & & $0.09 * * *$ & 0.52 \\
\hline & Eq. 4 & 11.79 & 11.90 & $-0.11 * * *$ & 0.52 \\
\hline
\end{tabular}

$\mathrm{RC}$, retail cut weight $(\mathrm{kg})$; \% RC, retail cut percentage; ELP, official equation currently used for predicting the lean yield percentage for Hanwoo carcasses;

FAT, trimmed fat weight (kg); \%FAT, trimmed fat percentage; BONE, trimmed bone weight (kg); \%BONE, trimmed bone percentage.

${ }^{1}$ Equation for the final step of four variable (coded by Eq. 4) and third step equation of three variable (coded by Eq. 3).

${ }^{2}$ Difference between predicted and observed value.

${ }^{3}$ Correlation coefficients between the predicted and observed values.

${ }^{4}$ Official equation currently used for predicting the lean yield percentage in Hanwoo carcass grading.

* Null hypothesis $\left(\mathrm{H}_{0}\right)$, differences are equal to zero $(* * \mathrm{p}<0.01$, *** $\mathrm{p}<0.001)$. 
and \% RC and a moderate positive correlation between MAR and \%FAT (Herring et al., 1994; Shackelford et al., 1995; Johnson and Rogers, 1997; Griffin et al., 1999; May et al., 2000; Greiner et al., 2003b).

When compared to the $\mathrm{R}^{2}$ values of the equations for $\% \mathrm{RC}, \% \mathrm{FAT}$, and \%BONE measured in percentages units, the $\mathrm{R}^{2}$ values corresponding to the RC, FAT, and BONE in $\mathrm{kg}$ units, respectively, were higher, of which trends had generally been shown in previous studies (Herring et al., 1994; Shackelford et al., 1995; Williams et al., 1997; Dikeman et al., 1998; Realini et al., 2001; Greiner et al., 2003b; Lee et al., 2005; Maeno et al., 2014). These results imply that the equations for RC or FAT constructed using carcass traits might be more accurate than the equations for \% RC and \%FAT. Further, CWT among the independent variables showed the strongest correlation in the equation with the highest $\mathrm{R}^{2}$ value as the best single predictor. The correlation coefficients for RC, FAT, and BONE with CWT, which were obtained using the square root of the $\mathrm{R}^{2}$ values of Eq. 1 for each weight variable, were 0.91, 0.77, and 0.69, respectively, in this study.

The official Korean equation for predicting \% RC includes the three independent variables of CWT, BFT, and EMA, which were the same independent variables used to construct Eq. 3 for RC and \% RC in this study. Lee et al. (2005 and 2008) and Choy et al. (2010) also developed equations using the same three independent variables to predict the $\mathrm{RC}$ and $\% \mathrm{RC}$ for Hanwoo steer carcasses. The $\mathrm{R}^{2}$ values in Eq. 3 for RC and \% RC were $87.1 \%$ and $23.5 \%$, respectively, in the present study, and these seem to concur with the values reported by Lee et al. (2005). However, the $\mathrm{R}^{2}$ value of $23.5 \%$ for $\% \mathrm{RC}$ is lower than the $54 \%$ reported by Choy et al. (2010). On the other hand, the $\mathrm{R}^{2}$ values reported for equations for \% RC with exotic beef carcasses ranged from $32.2 \%$ (Williams et al., 1997) to $75 \%$ (Cannell et al., 1999), which are generally higher than the $\mathrm{R}^{2}$ values from Eq. 3 and Eq. 4 in the present study. The different $R^{2}$ values from the various studies might be due to a number of factors, including different cattle types, feeding management, fat trimming level, carcass fatness, variables for equation development, and cutting procedures. Another plausible reason, which might be exclusive to the study on commercial data, was the inconsistent fat trimming level due to the purchaser's demand. In this study, the fat trimming of the retail cut was conducted within the $6 \mathrm{~mm}$ fat cover, but the fat trimming level could differ based on the purchaser's demand.

When the overall predictability of an equation is evaluated in terms of accuracy and precision, the RSD or the difference between the predicted and observed values were used to determine the level of accuracy, and the precision was determined through the comparison of $\mathrm{R}^{2}$ values or the correlation coefficients of the predicted and observed values
(Johnson and Rogers, 1977; Tedeschi, 2006). In this study, almost identical correlation coefficients were found for Eq. 3 and Eq. 4 regarding the predicted and observed values for all the dependent variables, which indicates that equal precision was achieved by Eq. 3 and Eq. 4. The small average difference in the absolute value for Eq. 3 implies that Eq. 3 is more accurate than Eq. 4 in predicting \% RC, BONE, and \%BONE; furthermore, the three variables in the current official equation for predicting RC were found to still be valid. However, compared to Eq. 3 and Eq. 4 for predicting $\% \mathrm{RC}$, a relatively high absolute value in the average difference for the ELP suggests that further study may be necessary to revise the official equation.

\section{CONCLUSION}

In stepwise process, the CWT was the most important trait for predicting RC, FAT, BONE, and \%BONE, and the BFT was the most important trait for predicting \% RC, \%FAT.

There are no differences in the model precision between the three- and four-variable equations for predicting all six dependent variables, and the model accuracy is similar for the prediction of RC, FAT, and \%FAT; however, threevariable equation (Eq. 3) is more accurate than the fourvariable equation for predicting $\% \mathrm{RC}, \mathrm{BONE}$, and \%BONE.

We concluded that Eq. 3, which has three variables, might be the optimal choice for practical use in predicting the six dependent variables, and this should facilitate the investigation of new variables with easy and cost-effective measurements in order to increase the precision of the equations for predicting percentage variables, such as $\% \mathrm{RC}, \% \mathrm{FAT}$, and \%BONE. The three variable equations included CWT, BFT, and EMA may be used for predicting lean and fat composition of Hanwoo carcasses and might be target variables for improving lean yield productivity of Hanwoo.

\section{CONFLICT OF INTEREST}

We certify that there is no conflict of interest with any financial organization regarding the material discussed in the manuscript.

\section{ACKNOWLEDGMENTS}

This study was supported by 2014 Research Grant from Kangwon National University (No. 120141398).

\section{REFERENCES}

Anderson, B. B., H. Busk, J. P. Chadwick, A. Cuthbertson, G. A. J. Fursey, D. W. Jones, P. Lewin, C. A. Miles, and M. G. Owen. 1983. Comparison of ultrasonic equipment for describing beef 
carcass characteristics in live cattle (report on a joint ultrasonic trial carried out in the U. K. and Denmark). Livest. Prod. Sci. 10:133-147.

Cannell, R. C., J. D. Tatum, K. E. Belk, J. W. Wise, R. P. Clayton, and G. C. Smith. 1999. Dual-component video image analysis system (VIASCAN) as a predictor of beef carcass red meat yield percentage and for augmenting application of USDA yield grades. J. Anim. Sci. 77:2942-2950.

Choy, Y. H., S. B. Choi, G. J. Jeon, H. C. Kim, H. J. Chung, J. M. Lee, B. Y. Park, and S. H. Lee. 2010. Prediction of retail beef yield using parameters based on Korean Beef Carcass Grading Standards. Korean J. Food Sci. Anim. Resour. 30:905-909.

Dikeman, M. E., L. V. Cundiff, K. E. Gregory, K. E. Kemp, and R. M. Koch. 1998. Relative contributions of subcutaneous and intermuscular fat to yield and predictability of retail product, fat trim, and bone in beef carcasses. J. Anim. Sci. 76:1604-1612.

Drennan, M. J., M. McGee, and M. G. Keane. 2008. The value of muscular and skeletal scores in the live animal and carcass classification scores as indicators of carcass composition in cattle. Animal 2:752-760.

Greiner, S. P., G. H. Rouse, D. E. Wilson, L. V. Cundiff, and T. L. Wheeler. 2003a. Accuracy of predicting weight and percentage of beef carcass retail product using ultrasound and live animal measures. J. Anim. Sci. 81:466-473.

Greiner, S. P., G. H. Rouse, D. E. Wilson, L. V. Cundiff, and T. L. Wheeler. 2003b. Prediction of retail product weight and percentage using ultrasound and carcass measurements in beef cattle. J. Anim. Sci. 81:1736-1742.

Griffin, D. B., J. W. Savell, H. A. Recio, R. P. Garrett, and H. R. Cross. 1999. Predicting carcass composition of beef cattle using ultrasound technology. J. Anim. Sci. 77:889-892.

Herring, W. O., S. E. Williams, J. K. Bertland, L. L. Benyshek, and D. C. Miller. 1994. Comparison of live and carcass equations predicting percentage of cutability, retail product weight, and trimmable fat in beef cattle. J. Anim. Sci. 72:1107-1118.

Hickey, J. H., M. G. Keane, D. A. Kenny, A. R. Cromie, and R. F. Veerkamp. 2007. Genetic parameters for EUROP carcass traits within different groups of cattle in Ireland. J. Anim. Sci. 85:314321.

Johnson, D. D. and A. L. Rogers. 1997. Predicting the yield and composition of mature cow carcasses. J. Anim. Sci. 75:18311836.

Kauffman, R. G., M. E. Van Ess, R. A. Long, and D. M. Schaefer. 1975. Marbling: Its use in predicting beef carcass composition. J. Anim. Sci. 40:235-241.

Kim, J. B. and C. Lee. 2000. Historical look at the genetic improvement in Korean cattle - Review -. Asian Australas. J. Anim. Sci. 13:1467-1481.
Koh, D., J. Lee, S. Won, C. Lee, and J. Kim. 2014. Genetic relationships of carcass traits with retail cut productivity of Hanwoo cattle. Asian Australas. J. Anim. Sci. 27:1387-1393.

Lee, J. M., Y. M. Yoo, B. Y. Park, H. S. Chae, D. H. Kim, Y. K. Kim, and Y. I. Choi. 2005. Study on the carcass yield grade of Hanwoo. J. Anim. Sci. Technol. 47:261-270.

Lee, J. M., K. H. Hah, J. H. Kim, S. H. Cho, P. N. Seong, M. O. Jung, Y. Cho, B. M. Park, D. H. Kim, and C. N. Ahn. 2008. Study on the carcass yield grade traits and prediction of retail product weight in Hanwoo beef. Korean J. Food Sci. Ani. Resour. 28:604-609.

Maeno, H., K. Oishi, T. Mitsuhashi, H. Kumagai, and H. Hirooka. 2014. Prediction of carcass composition and individual carcass cuts of Japanese Black steers. Meat Sci. 96:1365-1370.

May, S. G., W. L. Mies, J. W. Edwards, J. J. Harris, J. B. Morgan, R. P. Garrett, F. L. Williams, J. W. Wise, H. R. Cross, and J. W. Savell. 2000. Using live estimates and ultrasound measurements to predict beef carcass cutability. J. Anim. Sci. 78:1255-1261.

McPhee, M. J., J. W. Oltjen, J. G. Fadel, D. Perry, and R. D. Sainz. 2008. Development and evaluation of empirical equations to interconvert between twelfth-rib and kidney, pelvic, and heart fat respective fat weights and to predict initial conditions of fat deposition models for beef cattle. J. Anim. Sci. 86:1984-1995.

Minchin, W., F. Buckley, D. A. Kenny, M. G. Keane, L. Shalloo, and M. O'Donovan. 2009. Prediction of cull cow carcass characteristics from live weight and body condition score measured pre slaughter. Ir. J. Agric. Food Res.(check abbr.) 48:75-86.

MAFRA (Ministry of Agriculture, Food and Rural Affairs). 2009a. The grading standards for livestock products. Official Announcement 2009-344 (In Korean), Seoul, Korea.

MAFRA (Ministry of Agriculture, Food and Rural Affairs). 2009b. Standards for fabrications of saleable meat products. Official Announcement 2009-49 (In Korean), Seoul, Korea.

Realini, C. E., R. E. Williams, T. D. Pringle, and J. K. Bertrand. 2001. Gluteus medius and rump fat depth as additional live animal ultrasound measurements for predicting retail product and trimmable fat in beef carcasses. J. Anim. Sci. 79:1378-1385.

Shackelford, S. D., L. V. Cundiff, K. E. Gregory, and M. Koohmaraie. 1995. Predicting beef carcass cutability. J. Anim. Sci. 73:406-413.

Tedeschi, L. O. 2006. Assessment of the adequacy of mathematical models. Agric. Syst. 89:225-247.

Williams, R. E., J. K. Bertrand, S. E. Williams, and L. L. Benyshek. 1997. Biceps femoris and rump fat as additional ultrasound measurements for predicting retail product and trimmable fat in beef carcasses. J. Anim. Sci. 75:7-13. 